\title{
Death and taxes: using the latter to reduce the former
}

\author{
Kenneth E Warner
}

\section{Correspondence to} Professor Kenneth E Warner, Department of Health Management \& Policy, School of Public Health, University of Michigan, Ann Arbor, MI 48109-2029, USA; kwarner@umich.edu

Received 22 March 2013 Revised 16 April 2013 Accepted 24 April 2013 Published Online First 22 May 2013

To cite: Warner KE. Tob Control 2014;23:i4-i6.
As the old adage attributed to Benjamin Franklin puts it, there are only two things in life that are certain: death and taxes. In the case of cigarette smoking, they are closely related. Raising cigarette prices, primarily by increasing cigarette taxes, reduces smoking, and thereby reduces smokingproduced death and disability. Indeed, there is no more effective weapon in the arsenal of evidencebased tobacco control policies. Taxation has become a First Principle of tobacco control worldwide, hailed by the World Bank's 1999 'bible' of international tobacco control, Curbing the Epidemic: Governments and the Economics of Tobacco Control, ${ }^{1}$ and embodied in Article 6 of the Framework Convention on Tobacco Control. ${ }^{2}$ Virtually everyone engaged in tobacco control now understands the importance of keeping cigarette prices high and the role of raising taxes in doing so.

It was not always so. In the late 1970 s and early 1980s, many public health professionals believed that using taxation to reduce smoking was ineffective and even repugnant: for both 'moral' and practical reasons, discouraging smoking, they concluded, had to rely on important intrinsic considerations, not extrinsic factors like price. Smokers, they felt, should quit because of their concern for their own health or to ensure their children that they would still be around as the children grew to adulthood. Furthermore, they were convinced that taxation would have little impact because smokers were addicted, and therefore, would not change their behaviour in response to higher prices. ${ }^{3}$

The origins of the end of aversion to taxation as a tool of effective tobacco control lie in the publication of two research articles by Eugene Lewit and his colleagues using sophisticated econometric methods. The first, published in 1981, demonstrated that American teenagers' smoking was very price sensitive: for every $10 \%$ increase in price, the authors estimated that smoking 'participation' (prevalence) by 12-17-year-olds would decrease by $12 \%$, while the teens' total demand for cigarettes would decrease by $14 \% .^{4}$ The second study, published a year later, concluded that for adults, a $10 \%$ price increase would induce a decrease in the demand for cigarettes by $4.2 \%,{ }^{5}$ an estimate that has stood the test of time for developed nations. ${ }^{67}$ Three years later, I translated these findings into their stark implications for public policy in the US. Congressional legislation had dictated that a temporary doubling of the federal cigarette excise tax to 16 cents per pack-a short-term revenue measure-would end in 1985, with the tax reverting to its previous level of 8 cents per pack. Using the findings of Lewit et al, but employing methods and language more accessible to the general public, I demonstrated that if permitted to occur, the halving of the tax would induce two million additional Americans to smoke, including more than 460000 teens, with more than 480000 additional premature smokingproduced deaths occurring in the future. ${ }^{8} 9$ Through a well-orchestrated advocacy effort by Washington-based public health groups, this analysis contributed to the US Senate's decision to make the tax increase permanent. ${ }^{3}$

This direct application of findings from research on cigarette price and consumption-and a subsequent successful advocacy campaign to raise the cigarette tax in Canada, which also relied on such analysis-altered public health attitudes towards using tax to influence smoking. ${ }^{3}$ It also inaugurated an era of more intensive research on tax, price and smoking, with well over 100 studies documenting the effects of taxation, through its impact on price, on smoking. ${ }^{7}$ Early on, studies derived almost exclusively from developed countries' experiences, focusing on price elasticity of cigarette demand in general, with interest in how elasticity varied by age, gender and occasionally socioeconomic status. Over time, however, the research began to address more nuanced questions: when prices are raised on one tobacco product (eg, cigarettes), is the demand for other tobacco products affected (eg, smokeless tobacco)? Yes, it increases. ${ }^{10}$ How does addiction affect price responsiveness? This question spawned a 'boomlet' in 'rational addiction' studies. These sometimes controversial studies suggested that the long-run price elasticity may be as much as twice the conventionally estimated short-run elasticities. ${ }^{11}$ What compensatory behaviours might smokers take in response to price increases? According to one study, they might switch to higher nicotine cigarettes so that they could get their daily dose of nicotine from fewer cigarettes. ${ }^{12}$ And so on.

Surely, one of the most important developments in this literature has been the relatively recent emergence of a body of research on the effects of tax and price on smoking in low-income and middle-income countries (LMICs). Often reflecting severe data limitations on both cigarette price and consumption, as well as the lack of a welldeveloped indigenous research infrastructure, some of the earliest studies were quite primitive in nature or heroic in approach. Notably, for example, in 1990 a complete lack of data on cigarette and tobacco price forced Chapman and Richardson ${ }^{13}$ to estimate excise tax elasticities of demand for cigarettes and tobacco in Papua New Guinea. Observing that price elasticities had to be larger than excise tax elasticities, they inferred from their 
quite precise estimates of the latter- -0.71 for cigarettes and -0.50 for non-cigarette tobacco-a generalised conclusion that price elasticities had to be considerably larger (in absolute value) than those previously calculated for developed countries.

Since that very early study, research on the relationship between tax/price and smoking in LMICs has grown substantially in both quantity and methodological sophistication, ${ }^{7}$ consistent with a more general dramatic growth in tobacco control research in LMICs and by LMIC authors in recent years. ${ }^{14}$ The indigenous research structure is improving in LMICs, as is the data collection. Thanks to the support by organisations such as the Rockefeller Foundation and, most recently, the Bloomberg Initiative to Reduce Tobacco Use, ${ }^{15}$ scholars in LMICs are receiving training on econometric research methods and grant support to carry out studies.

This development is essential to the future of effective tobacco control worldwide. Government officials in LMICs will be far more responsive to studies deriving directly from their countries' data than to more general pronouncements on the effect of taxation based on studies from developed countries. Country-specific studies not only have more credibility in the eyes of government officials, but also permit more precise calculations as to how specific tax increases will affect government revenues, smoking-related healthcare costs, etc. Tobacco control research has had a discernible impact on policy and tobacco use in the world's affluent nations. ${ }^{16}$ It must now play a similar role in those less affluent countries in which the future of the smoking disease pandemic is brewing.

In some ways, the early scholars examining the relationship between price and cigarette consumption had it far easier than today's researchers. In countries like the USA, where much of the early research occurred, the product (the cigarette) was relatively homogeneous (there were many fewer brands of cigarettes, fewer brand variants, fewer cigarette-like combustible alternatives and fewer novel smokeless options). As well, price tended to be quite consistent across brands. Today, smokers confront a sometimes bewildering array of cigarette and noncigarette tobacco options. Prices in many countries vary widely, prices vary from one country to its immediate neighbours, and price discounting and black and grey markets make ascertainment of actual prices paid, and actual consumption for that matter, far more difficult. Thus, a relatively new challengeand an important one for the evolution of effective tobacco control-is to understand how smokers respond to tax increases in environments in which they have alternatives to simply paying the higher tax. The proliferation of discounted brands has increased options; so too has the availability of cigarettes purchased over the internet. In some countries, indigenous peoples sell cigarettes at tax-free prices, and smokers find it easy to purchase cigarettes on their reservations. In other countries, roll-your-own tobacco can compete with manufactured cigarettes, the latter frequently featuring higher taxes. Duty-free cigarettes, cigarette smuggling and smokers simply crossing borders to purchase cigarettes further complicate both analysis of price response and tobacco control itself.

For this reason, the present volume is especially timely and welcome. While the issue of tax evasion and avoidance-and tax response more generally-has been addressed in previous studies, I am aware of no previous collection of studies in which a wide array of evasion and avoidance behavioural responses are addressed in multiple countries, both developed nations and LMICs. The papers in this volume do not afford simple answers to what are, after all, quite complicated questions. Findings are not always consistent with expectation or, for that matter, with those of other papers in the volume, but the compendium does provide a treasure trove of empirical evidence pertaining to behavioural responses to taxes and differential prices, and it offers us a more informed opportunity to address the myriad policy questions that relate to tobacco taxation and to tax evasion and avoidance.

Quite independent of its substantive contributions, the volume marks an important maturation in the field of tobacco control research: until quite recently, research by LMIC authors was a relative rarity. ${ }^{14}$ This volume demonstrates that LMIC authors can join with those from developed countries as full partners in addressing a complex set of tobacco control issues. In part that has been made possible by the aforementioned training and grant opportunities now available to research colleagues in LMICs. In the present instance, however, another feature of the research landscape integral to the evolution of the volume warrants explicit mention as well, and indeed praise: these papers represent the latest instalment in the wealth of research emanating from the International Tobacco Control Policy Evaluation Project ${ }^{17}$ - universally known within the tobacco control policy research community simply as the ITC (International Tobacco Control) project. The brainchild of Professor Geoffrey Fong, one of this volume's editors and authors, ITC is an international cohort survey of tobacco use that develops country-specific and crosscultural comparative research directed at evidence-based tobacco control policy making. Administered in more than 20 countries representing half of the world's population and a majority of its tobacco users, ITC is devoted specifically to providing evidence-based support for Framework Convention on Tobacco Control policies. Prolific in its productivity, ITC represents one of the greatest assets ever developed in the field of tobacco control research. The present volume shows us how and why.

To conclude with where we began, death and taxes are both inevitable. But tobacco-produced deaths are not. And taxes on cigarettes and other tobacco products-large taxes, raised frequently - can go a long way, if not all the way, ${ }^{18}$ to ensuring a substantial and continuing decline in the number of smokingproduced deaths. For that to occur, we need to convince governmental authorities of the public health and fiscal wisdom of raising taxes, and we need to learn how to levy those taxes in a manner that will minimise their avoidance through means other than not smoking. The papers in this volume provide evidence that will help us in seeking to achieve these goals.

Contributors KW conceived and wrote this commentary.

Competing interests None.

Provenance and peer review Not commissioned; externally peer reviewed.

\section{REFERENCES}

1 Jha P, Chaloupka FJ, eds. Curbing the epidemic: governments and the economics of tobacco control. Washington: World Bank, 1999.

2 World Health Organization. WHO Framework Convention on Tobacco Control. http:/l whqlibdoc.who.int/publications/2003/9241591013.pdf (accessed 8 Mar 2013).

3 Scott E. From research to policy: the cigarette excise tax. Harvard University, Kennedy School of Government Case Program \#C16-93-1233.0, 1993.

4 Lewit EM, Coate D, Grossman M. The effects of government regulation on teenage smoking. J Law Econ 1981;24:545-69.

5 Lewit EM, Coate D. The potential for using excise taxes to reduce smoking. J Health Econ 1982:1:121-45.

6 Chaloupka FJ, Yurekli A, Fong GT. Tobacco taxes as a tobacco control strategy. Tobacco Control 2012;21:172-80.

7 International Agency for Research on Cancer. IARC Handbooks of Cance Prevention, Tobacco Control, Volume 14: Effectiveness of Tax and Price Policies in Tobacco Control. Lyon, France: International Agency for Research on Cancer, 2011. 
http://apps. who.int/bookorders/anglais/detart1.jsp?sesslan=1\&codlan=1\&codcol= 76\&codcch $=30$ (accessed 8 Mar 2013).

8 Warner KE. Consumption impacts of a change in the federal cigarette excise tax. In: The cigarette excise tax. Cambridge, MA: Institute for the Study of Smoking Behavior and Policy, Harvard University, 1985:88-105.

9 Warner KE. Smoking and health implications of a change in the federal cigarette excise tax. JAMA 1986;255:1028-32.

10 Ohsfeldt RL, Boyle RG, Capilouto El. Effects of tobacco excise taxes on the use of smokeless tobacco products. Health Econ 1997;6:525-32.

11 Chaloupka FJ, Warner KE. The economics of smoking. In: Culyer AJ, Newhouse JP, eds. Handbook of health economics. v. 1B. Amsterdam: Elsevier, 2000:1539-627.

12 Evans WM, Farrelly MC. The compensating behavior of smokers: taxes, tar, and nicotine. RAND J Econ 1998;29:578-95.
13 Chapman S, Richardson J. Tobacco excise and declining tobacco consumption: the case of Papua New Guinea. Am J Public Health 1990;80:537-40.

14 Warner KE, Tam J, Kulton SM. Growth in publications in Tobacco Control by lowand middle-income authors. Tobacco Control 2013 Published Online First: 3 Jan 2013. doi:10.1136/tobaccocontrol-2012-050762

15 Bloomberg Initiative to Reduce Tobacco Use Grants Program. http:/l tobaccocontrolgrants.org/ (accessed 8 Mar 2013).

16 Warner KE, Tam J. The impact of tobacco control research on policy: 20 years of progress. Tobacco Control 2012;21:103-9.

17 International Tobacco Control Policy Evaluation Project. http://www.itcproject.org/ (accessed 8 Mar 2013).

18 Warner KE, Mendez D. Tobacco control policy in developed countries: today, yesterday and tomorrow. Nicotine Tobacco Res 2010;12:876-87. 